\title{
Interactive comment on "Stress Characterization and Temporal Evolution of Borehole Failure at the Rittershoffen Geothermal Project” by Jérôme Azzola et al.
}

\section{Anonymous Referee \#2}

Received and published: 30 April 2019

The authors present a detailed study in orientation and magnitude of the local stress field at the geothermal site of Rittershoffen in France, near the well-known site Soultzsous-Forêt. The manuscript focuses on the temporal evolution of borehole breakouts and drilling induced tension fractures using acoustic images of two boreholes acquired by Ultrasonic Borehole Imager in 2012, 2013 and 2105. The manuscript is interesting and provides an important contribution for the understanding of the time-dependent deformation. In this form the manuscript is not ready for publication. Please see my comments. 
investigation image datasets from two boreholes GRT-1 and GRT-2. In the manuscript the analysis as well as the description and the discussion of the results are mainly focused only on GRT-1. I suggest the authors to show only the analysis on GRT-1 well. In case the author want to continue keep also the GRT-2 and detailed analysis of the datasets of this borehole is requested. The analysis must be related to the inclined borehole taking into account the orientation of the principal stresses in an inclined borehole. 2. The authors show in Figure 15 the magnitude of Sv, Sh and SH from $2000 \mathrm{~m}$ to $2500 \mathrm{~m}$ of GRT-1. To calculate the Sv magnitude the authors used equation (6). The Sv curve is presented as if it were made using a fixed value of $2440 \mathrm{~kg} / \mathrm{m} 3$ for the entire well. Can you explain why? At $2300 \mathrm{~m}$ using equation (6) as the author wrote the value Sv is $54.37 \mathrm{MPa}$, but using the value of $2570 \mathrm{~kg} / \mathrm{m} 3$ (Table 3) corresponding to the granite rock at a depth of $2200 \mathrm{~m} \mathrm{~Sv}$ is $58.28 \mathrm{MPa}$. I suggest redrawing figure 15 showing the entire section of the GRT-1 between 0 and $2562 \mathrm{~m}$ (TVD). Furthermore in line 387 the authors should specify that the density value shown in equation (6) is related to the Jurassic rocks between 1172 and $1447 \mathrm{~m}$ of GRT-1 as an example, but that the Sv was calculated taking into account the density values of the different rocks at different depths. No Figure for GRT-2. If the authors want to include this well they have to show the data and results.

Minor comments: 1. I suggest that the figures and tables have the same MD or TVD depths, or that both are reported. For example, Table 3 shows lithologies and densities relative to TVD depths, while if I look at the stratigraphy in Figure 8, the lithologies refer to MD depths. 2. Please include also the fractures distribution (number, dip, dip azimuth) highlighting the main faults or fracture zone to better understand the borehole breakout rotation and7or deviation from the mean of Sh. 3. The value from hydraulic test at GRT-1 differs from the data from the boreholes GPK1. Could you explain better the reason? Please add also this Sh- value from GRT1 in Figure 15 4. The caption of figure 13 refers to figure 12 . Whereas the caption of figure 12 refers to figure 13. Please modify. 5. Line 16 GRT-2 instead of GRT2 6. Line $162500 \mathrm{~m}$ instead of $2500 \mathrm{~m} \mathrm{7.} \mathrm{Line} 40$ provide an indirect infor- 
mation instead of provide a indirect information 8. Line 90 WSM released in 2016 no in 2008. Please update the reference and cite as: Heidbach, Oliver; Rajabi, Mojtaba; Reiter, Karsten; Ziegler, Moritz; WSM Team (2016): World Stress Map Database Release 2016. GFZ Data Services. http://doi.org/10.5880/WSM.2016.001 (http://dataservices.gfz-potsdam.de/wsm/showshort.php?id=escidoc:1680890) 9. Line 120 grT-1 instead of GRT 1 10. Lines 142-143: please specify which failure condition 11. Lines 307-309 Please insert one or more figures to confirm what has been said. 12. Line 183: why the authors grouped the Triassic sandstone in a single category? Please add in the manuscript the reason: no alteration, homogeneous lithology, no fractures, etc 13. Line $387 \mathrm{~Sv}[\mathrm{MPa}]=0,024{ }^{*} \mathrm{z}[\mathrm{m}]-0,83$ or Sv $[\mathrm{MPa}]=0.024{ }^{*} \mathrm{z}$ [m] -0.83 but no one value as dot and the other a comma. In order not to confuse the reader, I suggest to use the asterisk (or an $\mathrm{x}$ ) as a multiplication sign instead of the point. 14. Line 533 please $50 \mathrm{~m}$ instead of $50 \mathrm{~m} \mathrm{15}$. Line 573 please add a dot after correlation technique 16. Line 579 please add the year of the reservoir stimulation 17. Figure 1: legend: the reference is WSM 2016 not 2006 Helmholtz-Centre Potsdam GFZ. Inset with the sketch of GRT-1 and GRT-2 boreholes: the lithology is not clear, some writings overlap. It would be good if the stratigraphy had the same colours as the geological profile. Highlight the trajectory of the wells on the geological profile. Caption: Heidbach et al., 2016. Cite as: Heidbach, Oliver; Rajabi, Mojtaba; Reiter, Karsten; Ziegler, Moritz; WSM Team (2016): World Stress Map Database Release 2016. GFZ Data Services. 18. Figure 2: Please add two separated scales for radius $(\mathrm{mm})$ and for width $\left(^{\circ}\right)$ 19. Figure 3 : show directly in the figure $a, b, c, d$, the artefacts (signal loss, stick slip). 20. Figure 14: please add the fractures as Tadpole related to this section. 21. Figure 15: Please remove the lithology from inside the figure but add it as litho column to the side of the figure. Please add the fractures as Tadpole related to this section. Is the deviation of the stress values between 2250 and $2380 \mathrm{~m}$, more or less, due to the presence of fractures? 22. Figure 18: Please remove the lithology from inside the figure but add it as litho column to the side of the figure. The symbols of Sh and Sv of GRT-2 are not very clear in the figure. Please change the symbol.

Interactive comment
Printer-friendly version

Discussion paper 
Interactive comment 